\title{
Capacidade de combinação entre linhas tetraplóides e diplóides de melancia $^{1}$
}

\author{
Flávio F. de Souza ${ }^{2}$; Manoel Abilio de Queiróz ${ }^{3}$; Rita de Cássia de S. Dias ${ }^{3}$
}

${ }^{2}$ Embrapa Rondônia, C. Postal 406, 78.900-970 Porto Velho-RO. E-mail: flaviofs@cpafro.embrapa.br; ${ }^{3}$ DTCS - UNEB, C.Postal 171, 48.900-000 Juazeiro-BA. E-mail: fqueiroz@netcap.com.br

\section{RESUMO}

A capacidade de combinação entre três genitores tetraplóides (LT7-48.1, LT9-24.1 e LTCC-24) e quatro diplóides de melancia ('Crimson Sweet', 'Pérola', 'New Hampshire Midget' e 'Charleston Gray') foi avaliada num esquema de cruzamentos dialélicos parciais. Utilizou-se delineamento de blocos casualizados, com três repetições, formadas por parcelas de sete plantas. Genitores e $F_{1}$ 's foram avaliados quanto ao número de dias para o aparecimento da primeira flor masculina e feminina, número de frutos por planta, comprimento da rama principal, massa média dos frutos, teor médio de sólidos solúveis na polpa, diâmetros transversal e longitudinal do fruto, espessura da casca do fruto na região do pedúnculo e na região da cicatriz floral, cor da polpa e ocorrência de ocamento no fruto. Os genitores, tanto diplóides como tetraplóides, apresentaram-se bastante divergentes quanto às características estudadas. Os efeitos da capacidade geral de combinação (CGC) foram superiores aos efeitos da capacidade específica de combinação (CEC) para a maioria dos caracteres, especialmente daqueles relacionados com a produção da planta, indicando a maior importância dos efeitos gênicos aditivos. No entanto, algumas características, como precocidade e ocamento de frutos tiveram controle gênico não aditivo e, portanto, a avaliação e seleção de linhagens em combinações híbridas permitirão a síntese de híbridos triplóides superiores.

Palavras-chave: Citrullus lanatus, melancia sem sementes, cruzamento dialélico.

\begin{abstract}
Combining ability among tetraploid and diploid lines of watermelon

Combining ability of three tetraploid (LT7-48.1, LT9-24.1 and LTCC-24) and four diploid lines of watermelon ('Crimson Sweet', 'Pérola', 'New Hampshire Midget' and 'Charleston Gray') was evaluated using a partial diallel scheme. A randomized block design, with three replications and seven plants in each field plot was used. Parents and $F_{1}$ 's were evaluated regarding the number of days to the set of the first male and female flower, the number of fruits per plant and the length of the main vine, fruit mean weight, total soluble solids, transversal and axial fruit diameter, rind thickness at the stem and at the scar flower regions, flesh color and hollow heart. The tetraploid and diploid parents were diversified regarding the traits studied. The GCA effects were much higher than the SCA effects for most of the characters analyzed, particularly, for characters related to plant yield, showing the major relevance of the additive genetic effects. However, some traits like earliness and hollow heart presented non-additive genetic effects and, therefore, evaluation and selection of lines in hybrid combinations will allow the synthesis of superior watermelon triploid hybrids.
\end{abstract}

Keywords: Citrullus lanatus, seedless watermelon, diallel cross.

(Recebido para publicação em 28 de novembro de 2001 e aceito em 27 de agosto de 2002)

\begin{abstract}
A melancia (Citrullus lanatus (Thunb) Mansf.) é uma cucurbitácea de grande importância econômica, sendo cultivada em vários países do mundo. A produção mundial está estimada em aproximadamente 29,6 milhões de toneladas de frutos (FAO, 1995). No Brasil, em 2000, a área plantada foi de 81.022 hectares e a produção total foi superior a 226 milhões de frutos (IBGE, 2001).
\end{abstract}

Nos últimos anos, tem-se observado o crescimento da participação das cultivares apirênicas, dentro do mercado de melancia, sobretudo na Europa, Estados Unidos e Japão. Essas cultivares diferem das tradicionais por apre- sentarem sementes rudimentares, não lignificadas, que são facilmente consumidas com a polpa do fruto. Nos Estados Unidos, até 1991, a melancia sem sementes ocupava cerca de 5\% do mercado, com potencial estimado para ocupar de 15 a 50\% (Marr \& Gast, 1991). Atualmente, estima-se que o mercado dessa melancia naquele País seja superior a 20\%. Na Espanha, cerca de $90 \%$ da melancia apirênica produzida na região de Almeria destina-se à exportação, sobretudo para a Alemanha, França, países nórdicos e Reino Unido. Nessa região, a comercialização de melancia sem sementes aumentou de $18 \mathrm{mil}$ toneladas em 1993, para 80 mil toneladas em 1995 (Ferre \& Rodríguez, 1999).
No Brasil, a produção de melancia sem sementes é incipiente, de modo que a fruta praticamente não existe no mercado brasileiro. Alguns híbridos importados encontram-se disponíveis aos produtores, porém, apresentam problemas de adaptação, como baixa produtividade e suscetibilidade aos principais estresses bióticos da cultura no País. Esses problemas, associados ao elevado preço da semente e desconhecimento do mercado, não têm estimulado a produção de melancia sem sementes.

A condução de programas nacionais de melhoramento que utilizem germoplasma adaptado e coletado no Nordeste poderá ser boa alternativa para

\footnotetext{
${ }^{1}$ Parte da dissertação de mestrado apresentada pelo primeiro autor ao Programa de Pós-graduação em Botânica da Univ. Fed. Rural de Pernambuco.
} 
o desenvolvimento de cultivares que apresentem boas características de planta e fruto, que sejam resistentes às doenças e que possam ter as sementes disponibilizadas aos produtores por um preço mais acessível.

As sementes dos genótipos apirênicos de melancia são obtidas através do cruzamento de linhagens tetraplóides com linhagens diplóides. Portanto, a melancia sem sementes resulta de uma planta triplóide híbrida, que não apresenta sementes devido à formação de óvulos inviáveis em função de irregularidades meióticas (Kihara, 1951).

A produção de sementes triplóides de melancia envolve a maioria dos problemas comuns à produção de sementes híbridas em espécies monóicas, porém, uma tarefa difícil consiste na produção de linhas tetraplóides com boa capacidade de combinação (Wall, 1960). A capacidade combinatória de um determinado genitor pode ser medida em termos de capacidade geral de combinação (CGC) e capacidade específica de combinação (CEC), sendo a primeira determinada em relação ao desempenho médio de um genitor quando cruzado com outros genitores sendo associada à presença de efeitos aditivos dos alelos e às associações epistáticas do tipo aditiva (Cruz \& Vencovsky, 1989). A capacidade específica de combinação refere-se a uma combinação particular entre dois genitores cujo desempenho está acima ou abaixo do esperado com base no desempenho médio de ambos e está associada aos efeitos de dominância e epistasia envolvendo desvios de dominância (Cruz \& Vencovsky, 1989; Cruz \& Regazzi, 1997).

Alguns métodos têm sido propostos para estimar a capacidade combinatória de linhagens a serem utilizadas em programas de melhoramento, sendo que a maioria dos modelos pressupõe herança dissômica, o que não se aplica no caso da melancia sem sementes, já que as linhagens tetraplóides apresentam herança tetrassômica. No entanto, no modelo de análise dialélica proposto por Griffing (1956) não são exigidas as condições de segregação diplóide, herança monogênica e genótipos homozigotos, possibilitando a obtenção de informações genéticas relevantes para o melho- ramento (Arunachalam, 1976). Na verdade, as capacidades geral e específica de combinação são parâmetros estatísticos que não dependem do nível de ploidia da espécie (Killick, 1977).

Considerando o exposto, este trabalho teve como objetivo estimar a capacidade de combinação entre genitores tetraplóides e diplóides de melancia, bem como analisar a importância dos resultados obtidos para futuros programas de melhoramento.

\section{MATERIAL E MÉTODOS}

Os experimentos para obtenção e avaliação dos híbridos triplóides foram conduzidos na Estação Experimental da Embrapa Semi-Árido, localizada em Petrolina (PE).

As sementes híbridas triplóides foram obtidas em cruzamentos artificiais entre genitores tetraplóides e diplóides. Quinze plantas, de cada um dos genitores tetraplóides LT7-48.1, LT924.1 e LTCC-24, foram cruzadas com 10 plantas dos genitores diplóides, 'Crimson Sweet' - CS, 'Pérola' - P, 'New Hampshire Midget' - NHM e 'Charleston Gray' - CG. As plantas diplóides foram utilizadas como polinizadoras devido à maior viabilidade do seu pólen.

Os genitores e doze híbridos triplóides foram avaliados em campo, usando o delineamento de blocos casualizados, com três repetições. O semeio foi realizado em bandejas de isopor, preenchidas com substrato à base de húmus e vermiculita. $\mathrm{O}$ transplantio foi realizado 16 dias após o semeio e foram colocadas sete plantas por parcela, no espaçamento de $3 \times 1 \mathrm{~m}$. Como polinizador dos híbridos triplóides, foi empregado um híbrido diplóide experimental, utilizando-se uma planta no início e outra no final de cada parcela. A colheita foi iniciada aos 66 dias após o transplantio, usando como indicador do ponto de colheita o secamento da gavinha.

Para avaliação das características, foram amostradas as cinco plantas centrais de cada parcela, com seus respectivos frutos. As plantas foram avaliadas quanto ao número de dias para o aparecimento da primeira flor masculina
(FM), número de dias para aparecimento da primeira flor feminina $(\mathrm{FF})$, número de frutos por planta (NF) e comprimento de rama principal $(\mathrm{CR}) \mathrm{em} \mathrm{cm}$. Os frutos foram avaliados quanto à massa média (MF) em kg; teor de sólidos solúveis (SS), tomado com refratômetro manual na parte central do fruto; diâmetro transversal (DT)em $\mathrm{cm}$, diâmetro longitudinal (DL) em cm, espessura da casca na região do pedúnculo (ECP) em cm e espessura da casca na região da cicatriz floral (ECF) em cm. Através de escalas de notas, foram avaliadas a cor da polpa (CP) $(1=$ vermelha; $2=$ vermelha clara; $3=$ rósea e $4=$ branca) e a incidência de ocamento na polpa do fruto (OP) $(1=$ isento de ocamento; $2=$ cavidade até $5 \%$ da polpa; $3=$ cavidade entre 6 e $20 \%$; $4=$ maior que $20 \%$ ).

A análise de variância foi realizada com os dados médios das parcelas para cada característica, considerando-se o modelo $\mathrm{Y}_{\mathrm{ij}}=\mu+\mathrm{T}_{\mathrm{i}}+\mathrm{B}_{\mathrm{j}}+\mathrm{e}_{\mathrm{ij}}$, onde, $\mathrm{Y}_{\mathrm{ij}}$ é a observação do i-ésimo tratamento do $\mathrm{j}$ ésimo bloco; $\mu$, o efeito da média geral; $\mathrm{T}_{\mathrm{i}}$, o efeito do i-ésimo tratamento; $\mathrm{B}_{\mathrm{j}}$, o efeito do j-ésimo bloco e $e_{i j}$ o efeito do erro experimental.

A análise dialélica foi realizada utilizando-se o programa GENES, segundo o modelo de pais e $\mathrm{F}_{1}$ 's, do tipo “top cross" com linhas e testadores, modificado por Geraldi \& Miranda-Filho (1988). Esse método caracteriza-se pela decomposição da soma de quadrados de tratamentos em somas de quadrados associadas à capacidade combinatória dos dialelos parciais que incluem os genitores (Cruz \& Regazzi, 1997), os quais foram divididos em dois grupos, sendo que os tetraplóides constituíram o grupo I e os diplóides o grupo II.

A análise de variância do dialelo foi realizada segundo o modelo:

$$
Y_{i j}^{\prime}=m+\frac{1}{2}\left(d_{1}+d_{2}\right)+g_{i}+g_{j}^{\prime}+s_{i j}+\varepsilon_{i}
$$

onde, $\mathrm{Y}{ }_{\mathrm{ij}}$ é a média do tratamento envolvendo o i-ésimo genitor do grupo I e o j-ésimo genitor do grupo II; $\mathrm{m}$, a média geral do dialelo; $\mathrm{d}_{1}$ e $\mathrm{d}_{2}$, os contrastes envolvendo médias dos grupos I e II; $g_{j}$, o efeito da capacidade geral de combinação do i-ésimo genitor do grupo I; g’, o efeito da capacidade geral de combinação do j-ésimo genitor do grupo II; $\mathrm{s}_{\mathrm{ij}}$, o efeito da capacidade específica de combinação do i-ésimo genitor do grupo 
Tabela 1. Quadrados médios das capacidades geral (CGC) e específica (CEC) de combinação de genitores diplóides (grupo I) e tetraplóides (grupo II), para doze características de planta e frutos de melancia obtidos em um esquema dialelo parcial. Petrolina, Embrapa Semi-Árido, 1999.

\begin{tabular}{|c|c|c|c|c|c|c|c|c|}
\hline \multirow{3}{*}{$\begin{array}{l}\text { Caracterís- } \\
\text { ticas }^{1}\end{array}$} & \multirow{3}{*}{$\begin{array}{l}\mathrm{CV}^{2} \\
(\%)\end{array}$} & \multirow{3}{*}{$\begin{array}{l}\text { F.V. } \\
\text { G.L. }\end{array}$} & \multicolumn{6}{|c|}{ Quadrados médios } \\
\hline & & & Tratamentos & Grupos & $\begin{array}{c}\text { CGC Grupo } \\
\text { I }\end{array}$ & $\begin{array}{c}\text { CGC Grupo } \\
\text { II }\end{array}$ & CEC IxII & Residuo \\
\hline & & & 18 & 1 & 2 & 3 & 12 & 36 \\
\hline$\overline{F M}$ & 3,95 & & $23,5679^{* *}$ & $262,4385^{* *}$ & $0,3950_{n s}$ & $2,0628_{n s}$ & $12,9004^{* *}$ & 2,1754 \\
\hline FF & 3,45 & & $21,7276^{* *}$ & $300,6001^{* *}$ & $16,6763^{*}$ & $1,7326_{\mathrm{ns}}$ & $4,3288_{n s}$ & 3,4025 \\
\hline $\mathrm{CR}(\mathrm{cm})$ & 8,91 & & $2,2907^{* *}$ & $0,8024 \mathrm{~ns}$ & $6,6612^{* *}$ & $1,2640^{* *}$ & $1,9430^{* *}$ & 0,2031 \\
\hline NF & 20,66 & & $23,0528^{* *}$ & $5,8278^{* *}$ & $119,4988^{* *}$ & $21,7099 * *$ & $8,7496 * *$ & 0,6077 \\
\hline MF (kg) & 13,29 & & $27,6974^{* *}$ & $14,1831^{* *}$ & $133,6982^{* *}$ & $47,0535^{* *}$ & $6,3177^{* *}$ & 0,8113 \\
\hline SS & 3,36 & & $7,8774^{* *}$ & 0,0299 ns & $45,2638^{* *}$ & $9,6814^{* *}$ & $1,8493^{* *}$ & 0,1209 \\
\hline $\mathrm{DT}(\mathrm{cm})$ & 3,78 & & $34,9028^{* *}$ & 1,2096 ns & $186,7538^{* *}$ & $64,0128^{* *}$ & $5,1246^{* *}$ & 0,6667 \\
\hline $\mathrm{DL}(\mathrm{cm})$ & 9,41 & & $99,3461^{* *}$ & $318,8585^{* *}$ & $230,5913^{* *}$ & $280,5639^{* *}$ & $13,8748^{* *}$ & 2,4135 \\
\hline $\mathrm{ECP}(\mathrm{cm})$ & 9,41 & & $0,2183^{* *}$ & $0,1057^{\mathrm{ns}}$ & $0,8488^{* *}$ & $0,1071^{*}$ & $0,1503^{* *}$ & 0,0320 \\
\hline $\mathrm{ECF}(\mathrm{cm})$ & 19,92 & & $0,0697^{* *}$ & $0,0655^{*}$ & $0,3388^{* *}$ & $0,0414^{* *}$ & $0,0322^{* *}$ & 0,0094 \\
\hline $\mathrm{CPF}$ & 10,30 & & $1,4611^{* *}$ & $0,0505_{n s}$ & $7,4151^{* *}$ & $2,2582^{* *}$ & $0,3870^{* *}$ & 0,0224 \\
\hline OP & 25,70 & & $1,0463^{* *}$ & $0,8591_{\mathrm{ns}}$ & $2,2287^{* *}$ & $0,2429_{n s}$ & $1,0657^{* *}$ & 0,2175 \\
\hline
\end{tabular}

ns/ Não significativo

* Significativo, a $5 \%$ de probabilidade, pelo teste $\mathrm{F}$.

** Significativo, a $1 \%$ de probabilidade, pelo teste $\mathrm{F}$.

${ }^{1 /} \mathbf{F M}=$ número médio de dias para o aparecimento da primeira flor masculina; $\mathbf{F F}=$ número médio de dias para o aparecimento da primeira flor feminina; $\mathbf{N F}=$ número médio de frutos por planta; $\mathbf{M F}=$ massa média de frutos; $\mathbf{S S}=$ teor de sólidos solúveis; $\mathbf{D T}=$ diâmetro médio transversal de frutos; $\mathbf{D L}=$ diâmetro médio longitudinal de frutos; $\mathbf{E C P}=$ espessura média da casca do fruto na região do pedúnculo; $\mathbf{E C F}$ $=$ espessura média da casca do fruto na região da cicatriz floral; $\mathbf{C P F}=$ cor média da polpa de frutos; $\mathbf{O P}=$ ocorrência de ocamento na polpa do fruto; $\mathbf{C R}=$ comprimento de rama principal.

${ }^{2 /}$ C.V. = Coeficiente de variação; F.V. = Fonte de variação; G.L. = Grau de liberdade

I e o j-ésimo genitor do grupo II e $\mathrm{e}_{\mathrm{ij}} \mathrm{o}$ erro experimental. Os valores de $g_{i}$ e $g_{j}$ foram estimados através das fórmulas:

$$
\begin{gathered}
\hat{g}_{i}=\frac{1}{q+4}\left[Y_{i .}+2 Y_{i 0}-\frac{1}{p}\left[Y_{H}+2 Y_{(1)}\right]-\right. \\
e \\
\hat{g}_{j}^{\prime}=\frac{1}{p+4}\left[Y_{j}+2 Y_{0 j}-\frac{1}{q}\left[Y_{H}+2 Y_{(2)}\right]\right.
\end{gathered}
$$

onde, $\mathrm{p}$ e q correspondem ao número de genitores dos grupos I e II respectivamente; $Y_{i}$ e $Y_{j}$ são os totais das q e p combinações híbridas do i-ésimo genitor do grupo I e do j-ésimo genitor do grupo II, respectivamente; $\mathrm{Y}_{\mathrm{i} 0}$ e $\mathrm{Y}_{0 \mathrm{j}}$ são as médias do i-ésimo genitor do grupo I e do jésimo genitor do grupo II, respectivamente; $Y_{H}$ é o total das pq combinações híbridas; $\mathrm{Y}_{(1)}$ e $\mathrm{Y}_{(2)}$ total das p médias dos genitores do grupo I e total das q médias dos genitores do grupo II. Os efeitos de $\mathrm{s}_{\mathrm{ij}}$ foram estimados segundo a fórmula

$$
\hat{s}_{i j}=Y_{i j}-\left[\hat{m}+\hat{g}_{i}+\hat{g}_{j j}+\frac{1}{2}\left(\hat{d}_{1}+\hat{d}_{2}\right)\right]
$$

\section{RESULTADOS E DISCUSSÃO}

As diferenças significativas verificadas na análise de variância, para todas as características avaliadas, indicam a presença de variabilidade genética entre os genótipos estudados (Tabela 1).

As diferenças significativas observadas na capacidade geral de combinação para todas as características avaliadas, exceto para florescimento feminino nos genitores tetraplóides e florescimentos feminino e masculino e ocamento da polpa dos frutos, nos diplóides, indicam que os genitores utilizados contribuíram diferentemente para a média dos híbridos, com relação à maioria dos caracteres estudados. Contudo, a não significância para algumas características nos genitores diplóides era esperada, tendo-se em vista que os mesmos são cultivares comerciais bastante selecionadas para precocidade e características do fruto.
O fato de os efeitos da capacidade geral de combinação superarem os da capacidade específica de combinação em todas as características avaliadas, exceto no florescimento masculino (Tabela 1), indica que a ação gênica aditiva foi predominante no controle da maioria das características para os genitores estudados. Assim, para o florescimento masculino nos genitores tetraplóides, as interações não-aditivas foram mais importantes do que as aditivas. A capacidade de combinação específica superior para o florescimento masculino e ocamento dos frutos, nos genitores diplóides, sugere que o controle genético desses caracteres é governado por ação gênica não aditiva, o que pode dificultar o processo seletivo das progênies para a síntese de híbridos.

Os caracteres relacionados com a produtividade e teor de açúcar apresentaram ação gênica aditiva. Avaliando a capacidade de combinação entre genótipos diplóides de melancia, dentre eles, 'Crimson Sweet', 'New 
Tabela 2. Estimativas dos efeitos da capacidade geral de combinação entre três genitores tetraplóides e quatro diplóides de melancia. Petrolina, Embrapa Semi-Árido, 1999.

\begin{tabular}{|c|c|c|c|c|c|c|c|c|c|c|c|c|}
\hline \multirow{2}{*}{ Genitores $^{1}$} & \multicolumn{12}{|c|}{ Características avaliadas } \\
\hline & $\mathrm{FM}^{2 /}$ & FF & CR & NF & MF & SS & DT & DL & ECP & ECF & CPF & OP \\
\hline LT7-48.1 & $-0,1417$ & $-0,4750$ & $-0,4042$ & $-1,5708$ & 2,0233 & 0,9958 & 2,2000 & 2,6125 & 0,1792 & 0,0042 & $-0,3333$ & $-0,2292$ \\
\hline LT9-24.1 & 0,1083 & $-0,4875$ & $-0,1917$ & $-0,9833$ & 0,5696 & 0,5708 & 0,9375 & 0,8125 & $-0,1958$ & $-0,1208$ & $-0,3083$ & 0,3458 \\
\hline LTCC-24 & 0,0333 & 0,9625 & 0,5958 & 2,5542 & $-2,5929$ & $-1,5667$ & $-3,1375$ & $-3,4250$ & 0,0167 & 0,1167 & 0,6417 & $-0,1167$ \\
\hline CS & $-0,0714$ & 0,3393 & 0,2464 & $-0,3929$ & 1,0118 & 0,4786 & 1,6214 & $-0,2893$ & 0,0929 & $-0,0071$ & $-0,1464$ & 0,0857 \\
\hline$P$ & $-0,4143$ & $-0,3464$ & $-0,2250$ & $-0,8357$ & 0,2718 & 0,2643 & 1,1643 & $-0,9036$ & $-0,0786$ & $-0,0214$ & $-0,2464$ & 0,0429 \\
\hline NHM & 0,2429 & 0,0821 & 0,1750 & 1,4786 & $-2,1911$ & $-1,0071$ & $-2,1929$ & $-3,7893$ & $-0,0214$ & $-0,0357$ & 0,4821 & $-0,1571$ \\
\hline CG & 0,2429 & $-0,0750$ & $-0,1964$ & $-0,2500$ & 0,9075 & 0,2643 & $-0,5929$ & 4,9821 & 0,0071 & 0,0643 & $-0,0893$ & 0,0286 \\
\hline
\end{tabular}

${ }^{1 /}$ Grupo II; genitores diplóides: $\mathbf{C S}=$ 'Crimson Sweet'; $\mathbf{P}=$ 'Pérola'; NHM = New Hampshire Midget; $\mathbf{C G}=$ 'Charleston Gray'.

${ }^{2} \mathbf{F M}=$ número médio de dias para o aparecimento da primeira flor masculina; $\mathbf{F F}=$ número médio de dias para o aparecimento da primeira flor feminina; $\mathbf{N F}=$ número médio de frutos por planta; $\mathbf{C R}=$ comprimento de rama principal; $\mathbf{M F}=$ massa média de frutos; $\mathbf{S S}=$ teor de sólidos solúveis; $\mathbf{D T}=$ diâmetro médio transversal de frutos; $\mathbf{D L}=$ diâmetro médio longitudinal de frutos; $\mathbf{E C P}=$ espessura média da casca do fruto na região do pedúnculo; $\mathbf{E C F}=$ espessura média da casca do fruto na região da cicatriz floral; $\mathbf{C P F}=$ Cor média da polpa de frutos; $\mathbf{O P}=$ ocamento na polpa do fruto;

Tabela 3. Estimativas dos efeitos da capacidade específica de combinação entre três genitores tetraplóides e quatro diplóides de melancia. Embrapa Semi-Árido, Petrolina (PE), 1999.

\begin{tabular}{|c|c|c|c|c|c|c|c|c|c|c|c|c|}
\hline \multirow{2}{*}{ Híbridos } & \multicolumn{12}{|c|}{ Características avaliadas } \\
\hline & $\mathrm{FM}^{3 /}$ & FF & CR & NF & MF & SS & DT & DL & ECP & ECF & CPF & OP \\
\hline $\mathrm{LT}-48.1^{1 /} \times \mathrm{CS}^{2 /}$ & 2,2737 & 0,5516 & $-0,3158$ & 0,1622 & 1,3593 & $-0,1092$ & 0,9922 & 1,3563 & 0,2265 & $-0,0895$ & 0,0351 & 0,5222 \\
\hline LT7-48.1 x P & 1,6166 & 0,6374 & 0,1556 & 0,5050 & 0,6493 & 0,3051 & 0,5493 & 0,5706 & 0,1979 & 0,0248 & 0,1351 & $-0,1349$ \\
\hline LT7-48.1 x NHM & 0,2594 & $-0,4912$ & 1,1557 & 0,4907 & $-0,2878$ & 1,1765 & 0,0065 & 0,6563 & 0,0408 & $-0,0609$ & $-0,4935$ & 0,2651 \\
\hline LT7-48.1 x CG & 1,6594 & $-0,6341$ & 0,7271 & $-0,5807$ & 2,3936 & 0,8051 & 2,1065 & 1,0849 & 0,1122 & 0,0391 & $-0,0221$ & 0,4794 \\
\hline LT9.24.1 x CS & 1,0237 & $-1,7359$ & 0,4717 & 0,2747 & $-0,1569$ & $-0,4842$ & $-0,6453$ & 0,3563 & $-0,0985$ & 0,0355 & 0,0101 & 0,3472 \\
\hline LT9.24.1 x P & 1,3666 & $-0,0502$ & 0,1431 & 0,3175 & 0,4031 & 0,0301 & 0,4118 & 1,3706 & 0,1729 & $-0,0502$ & 0,1101 & 0,6901 \\
\hline LT9.24.1 x NHM & 1,0094 & 0,2213 & 0,8431 & 0,6032 & $-0,5340$ & 0,6015 & $-0,5310$ & $-0,3437$ & 0,2158 & $-0,0359$ & $-0,6185$ & $-0,2099$ \\
\hline LT9.24.1 x CG & 1,4094 & $-1,0216$ & 0,1146 & 0,1318 & 0,0074 & 0,3301 & 0,3690 & $-1,1151$ & $-0,0128$ & 0,0641 & 0,2529 & 0,2044 \\
\hline LTCC-24 x CS & $-0,2013$ & $-1,8859$ & 0,9842 & 1,1372 & $-1,4744$ & $-0,7467$ & $-1,1703$ & $-1,4062$ & 0,1890 & 0,0980 & 0,1601 & 0,3097 \\
\hline LTCC-24 x P & 0,7415 & 0,7999 & 0,1556 & $-0,2200$ & $-1,1444$ & 0,4676 & $-1,2132$ & $-0,8919$ & 0,0604 & 0,0123 & $-0,4399$ & 0,6526 \\
\hline LTCC-24 x NHM & 0,4844 & $-0,6287$ & 0,0556 & 2,5657 & 0,2185 & 0,3390 & $-0,5560$ & $-0,2062$ & 0,0033 & 0,2266 & $-0,1685$ & 0,5526 \\
\hline LTCC-24 x CG & 2,0844 & $-0,4716$ & 0,3271 & 2,9943 & $-1,9901$ & $-0,7324$ & $-1,3560$ & $-4,7776$ & 0,2747 & 0,0266 & 0,2029 & 0,0669 \\
\hline
\end{tabular}

${ }^{1 /}$ Grupo I : genitores tetraplóides - LT7-48.1; LT9-24.1 e LTCC - 24; ${ }^{1 /}$ Grupo II; genitores diplóides: CS = 'Crimson Sweet'; P = 'Pérola'; NHM = New Hampshire Midget; CG = 'Charleston Gray'.

${ }^{3 /} \mathbf{F M}=$ número médio de dias para o aparecimento da primeira flor masculina; $\mathbf{F F}=$ número médio de dias para o aparecimento da primeira flor feminina; $\mathbf{N F}=$ número médio de frutos por planta; $\mathbf{C R}=$ comprimento de rama principal; $\mathbf{M F}=$ massa média de frutos; $\mathbf{S S}=$ teor de sólidos solúveis; $\mathbf{D T}=$ diâmetro médio transversal de frutos; $\mathbf{D L}=$ diâmetro médio longitudinal de frutos; $\mathbf{E C P}=$ espessura média da casca do fruto na região do pedúnculo; $\mathbf{E C F}=$ espessura média da casca do fruto na região da cicatriz floral; $\mathbf{C P F}=$ Cor média da polpa de frutos; $\mathbf{O P}=$ ocamento na polpa do fruto;

Hampshire Midget' e 'Charleston Gray', Ferreira (1996) também observou a predominância dos efeitos gênicos aditivos para o número de frutos por planta, massa média de fruto, diâmetro longitudinal do fruto, espessura da polpa, teor de sólidos solúveis e cor da polpa. Tais resultados asseguram a possibilidade da obtenção de linhagens elites através da seleção de indivíduos superiores dentro das populações diplóides e tetraplóides, com o objetivo de sintetizar híbridos triplóides comerciais. Entretanto, devese ter um cuidado especial na seleção de híbridos triplóides precoces e sem ocamento de frutos, devido à ação gênica não aditiva encontrada no controle desses caracteres.

Os efeitos positivos e negativos de CGC apresentados pelo genitor LTCC24 (Tabela 2), originário da poliploidização de um acesso não melhorado, sugerem que esse genitor poderá produzir híbridos triplóides que ten- 
dam a apresentar plantas mais tardias, muito vigorosas, altamente prolíficas, que produzem frutos pequenos com polpa de coloração rósea, menor teor de sólidos solúveis e menor ocorrência de ocamento.

$\mathrm{O}$ comportamento com relação à CGC (Tabela 2) para as características avaliadas demonstra que o genitor LT748.1 poderá produzir híbridos mais precoces, com plantas mais compactas, pouco prolíficas, de frutos grandes, com polpa mais doce e mais avermelhada e com menor ocorrência de ocamento, revelando o potencial desse genitor como fonte de obtenção de progênies tetraplóides superiores.

O genitor LT9-24.1 apresentou comportamento semelhante ao LT748.1 quanto aos efeitos da CGC, para a maioria dos caracteres avaliados, porém, apresentou diferença para número de frutos por planta, massa média de fruto e principalmente ocamento de fruto (Tabela 2). Efeitos positivos de CGC para ocorrência de ocamento indicam que o genitor poderá contribuir para aumentar a freqüência de frutos ocos nos cruzamentos de que participar, o que não é desejável, tendo-se em vista que essa característica reduz a qualidade da produção.

Os genitores diplóides 'Crimson Sweet', 'Pérola' e 'Charleston Gray' contribuíram para obtenção de híbridos pouco prolíficos, com alto teor de sólidos solúveis e coloração de polpa vermelha. O genitor 'New Hampshire Midget' contribuiu para o desenvolvimento de híbridos mais prolíficos, de frutos menores e com menor ocorrência de ocamento (Tabela 2). Resultados semelhantes também foram obtidos por Ferreira (1996), estudando híbridos diplóides, envolvendo esses genitores.

O desempenho de alguns híbridos, em termos de CEC, foi o que seria es- perado com base na CGC dos genitores (Tabela 3), o que revela maior nível de complementação alélica dos genitores cruzados, nos locos com alguma dominância (Vencovsky \& Barriga, 1992). A combinação híbrida LT7-48 x CG apresentou elevado efeito positivo de CEC para massa média de fruto e teor de sólidos solúveis, indicando ser a mais promissora para a produção de híbridos comerciais de frutos grandes (Tabela 3 ). De fato, as melhores combinações híbridas são aquelas que apresentam elevados valores de CEC provenientes de pais que apresentem altos valores de CGC (Cruz \& Regazzi, 1997).

A maioria dos híbridos não apresentou comportamento previsível com base na CGC dos genitores, como é possível observar em um exame detalhado dos demais caracteres analisados (Tabela 3 ). Esses resultados demonstram que, para a seleção de linhas endogâmicas, é preciso avaliá-las quanto ao comportamento individual para os caracteres considerados; porém, é necessário avaliar o comportamento em combinações híbridas. Para tal, poderá ser utilizado o processo de obtenção de linhagens através do método do híbrido críptico (Hallauer, 1967, citado por Bueno et al., 2001), no qual será possível explorar os efeitos das capacidades de combinação para os diversos caracteres de interesse do melhoramento, sejam eles governados por ação gênica aditiva ou não-aditiva.

\section{AGRADECIMENTOS}

Ao Conselho Nacional de Desenvolvimento Científico e Tecnológico $(\mathrm{CNPq})$, pela concessão da bolsa de mestrado; à Embrapa Semi-Árido, à Fundação de Amparo à Ciência e à Tecnologia - FACEPE e ao Banco do Nordeste, pelo suporte financeiro.

\section{LITERATURA CITADA}

ARUNACHALAM, V. Evaluation of diallel crosses by graphical and combining ability methods. The Indian Journal Genetics and Plant Breeding, v. 36, n. 3, p. 358-366, 1976.

BUENO, L.C.S.; MENDES, A.N.G.; CARVALHO, S.P. Melhoramento genético de plantas: princípios e procedimentos. Lavras: Universidade Federal de Lavras, 2001, 282 p.

CRUZ, C.D.; REGAZZI, A.J. Modelos biométricos aplicados ao melhoramento genético. Viçosa: UFV, Imprensa Universitária, 1997. 390 p.

CRUZ, C.D.; VENCONVSKY, R. Comparação de alguns métodos de análise dialélica. Revista Brasileira de Genética, Ribeirão Preto, v. 12, n. 2, p. 425-436, 1989.

FAO PRODUCTION YEARBOOK. Rome: FAO, v. 49 , p. $146,1995$.

FERRE, F.C.; RODRÍGUEZ, E.J.F. Influencia de patrones utilizados en el cultivo de sandía bajo plástico sobre la producción, precocidad y calidad del fruto en Almería. Disponível: La Rural Site (03 de ago. 1998). Disponível no site: $<$ www.larural.es/servagro/sta $>$. Consultado em 28/08/99.

FERREIRA, M.A.J.F. Análise dialélica em melancia Citrullus lanatus (Thunb.) Mansf. Jaboticabal, 1996. 83 f(Tese mestrado). UNESP FCAV.

GERALDI, I.O.; MIRANDA-FILHO, J.B. Adapted models for the analysis of combining ability of varieties in partial diallel crosses. Revista Brasileira de Genética, Ribeirão Preto, v. 11, p. 419-430, 1988.

GRIFFING, B. Concept of general and specific combining ability in relation to diallel crossing systems. Australian Journal of the Biological Science, v. 9, n. 4, p. 463-493, 1956.

IBGE. Produção Agrícola. Disponível: site Sistema IBGE de recuperação Automática - SIDRA (2001). Disponível no site: <http:// www.sidra.ibge.gov.br/cginbin $>$. Consultado em: 20/12/01.

KIHARA, H. Triploid watermelon, Journal of American Society for Horticultural Science, v. 58, p. 217-230, 1951.

KILLICK, R.J. Genetic analysis of several traits in potatoes by means of a diallel cross. Annals of Applied Biology, v. 86, p. 279-280, 1977.

MARR, C.W.; GAST, K.L.B. Reactions by consumers in a 'farmers' market to prices for seedless watermelon and ratings of eating quality. HortTechnology, v. 1, p. 105-106, 1991.

VENCOVSKY, R.; BARRIGA, P. Genética biométrica no fitomelhoramento. Ribeirão Preto: Sociedade Brasileira de Genética, 1992. 496 p.

WALL, J.R. Use of marker genes in producing triploid watermelons. Journal of the American Society for Horticultural Science, v. 76, p. 577581, 1960. 